\title{
Antitumor effect of the selective COX-2 inhibitor celecoxib on endometrial adenocarcinoma in vitro and in vivo
}

\author{
YITAO XIAO, YINCHENG TENG, RUI ZHANG and LAIMIN LUO \\ Department of Gynecology and Obstetrics, Shanghai Jiaotong University Affiliated Sixth People's Hospital, \\ Shanghai 200233, P.R. China
}

Received June 8, 2012; Accepted September 13, 2012

DOI: $10.3892 / 01.2012 .936$

\begin{abstract}
The aim of this study was to investigate the antitumor effect of the selective cyclooxygenase-2 (COX-2) inhibitor celecoxib on endometrial adenocarcinoma in mice. Various amounts of celecoxib were added to HEC-1B cells in vitro for different durations. Cell cycle and apoptosis were analyzed using flow cytometry. HEC-1B cytostasis, invasiveness and COX-2 expression were examined by MTT, transwell cabin and western blot assays, respectively. An in vivo human endometrial adenocarcinoma model was established in BALB/c nude mice using HEC-1B cells. For two weeks, the celecoxib groups were treated with celecoxib 2 or $4 \mathrm{mg} /$ day via oral administration and the control group was treated with saline. Tumor volume, growth curves and the inhibition rate (IR) were recorded. COX-2 expression levels and microvessel density (MVD) were investigated using an immunohistochemical technique. In the celecoxib groups, cell proliferation was significantly inhibited in a concentration- and time-dependent manner. The proportion of cells in the G0/G1 phase increased within $24 \mathrm{~h}$ after the addition of celecoxib whereas those in the $S$ and $\mathrm{G} 2 / \mathrm{M}$ phases decreased with an increasing apoptosis peak (sub-G1) and apoptosis rate. The microporous Matrigel-coated polycarbonate membrane of the Transwell cabin was traversable for the HEC-1B cells. The invasiveness was attenuated when the celecoxib concentration was increased. The tumor growth was also greatly inhibited when the celecoxib concentration was increased. The tumor IRs were 32.4 and $48.6 \%$ following treatment with 2 and $4 \mathrm{mg} /$ day celecoxib, respectively. COX-2 was mainly expressed in the cytoplasm of the tumor cells. In the celecoxib groups, the COX-2 expression levels were concentration-dependent. The COX-2 expression level and MVD decreased when the celecoxib concentration was increased. The results of dependability analysis revealed that the COX-2 expression level was positively correlated with
\end{abstract}

Correspondence to: Professor Laimin Luo, Department of Gynecology and Obstetrics, Shanghai Jiaotong University Affiliated Sixth People's Hospital, Shanghai 200233, P.R. China

E-mail: ytwcchina@163.com

Key words: adenocarcinoma, celecoxib, selective COX-2 inhibitor
MVD ( $\mathrm{r}=0.921 ; \mathrm{P}<0.01)$. The antitumor effect of celecoxib on endometrial adenocarcinoma in nude mice may be related to the inhibition of COX-2 expression and microangiogenesis.

\section{Introduction}

Endometrial carcinoma is a malignant epithelial carcinoma of the endometrium, which accounts for approximately $80 \%$ of adenocarcinomas. The growing incidence of endometrial carcinoma among younger generations worldwide jeopardizes the health of young females (1).

Cyclooxygenase (COX) is composed of two isoenzymes, namely COX-1 and COX-2. COX is a rate-limiting enzyme that catalyzes the transformation of arachidonic acid to prostaglandin $\mathrm{H}_{2}\left(\mathrm{PGH}_{2}\right) . \mathrm{PGH}_{2}$ is mainly expressed in normal tissues. However, the expression of COX-2 is induced by many exterior and interior blood vessel activators, including cytokines, growth factors and carcinogenic-promoting agents during inflammation, tissue damage and tumorigenesis.

Studies have shown that the genesis and development of endometrial carcinoma are closely related to COX-2. The expression of COX-2 has been reported to be increased in endometrial cancer tissue and this was associated with the inhibition of apoptosis and the promotion of angiogenesis (2). These results provided strong evidence for the potential clinical use of a selective COX-2 inhibitor in the treatment of endometrial carcinoma. JTE-522, a selective COX-2 inhibitor, has been shown to inhibit the proliferation of RL952 cells and induce their apoptosis (3). Wood et al investigated the effects of rofecoxib on endometrial carcinoma in vivo (4). Rofecoxib significantly inhibited the proliferation of endometrial carcinoma, but not its apoptosis. Celecoxib, a relatively new NSAID, selectively inhibits COX-2 but not COX-1, which minimizes undesired effects, including platelet functional disturbance, renal impairment and gastrointestinal reactions, caused by the long-term use of non-selective NSAIDs. The relatively low incidence of side effects with selective COX-2 inhibitors does not affect their widespread application in clinical practice.

Wei et al found that celecoxib effectively inhibited proliferation by inducing apoptosis (5). However, studies concerning the effects of celecoxib, in vivo and in vitro, on human endometrial carcinoma cells (HEC-1B) in mice are not available. Munir et al identified that the high expression level of COX-2 in HEC-1B cells was further increased 
by prostaglandin $\mathrm{E}_{2}\left(\mathrm{PGE}_{2}\right)(6)$. A cancer-bearing model involving hairless mice was successfully established by Gong et al by the subcutaneous inoculation of HEC1-B cells (7). To investigate the effect of celecoxib on the proliferation, invasion and apoptosis of HEC-1B cells, in vitro cell culturing and in vivo cancer-bearing models were used. Further information was obtained about the effect of celecoxib on the biological behavior of human endometrial adenocarcinoma. The findings may provide a new technique for controlling the development of endometrial carcinoma (8).

\section{Materials and methods}

Cell culture. The HEC-1B cell line (Shanghai Cell Bank, Chinese Academy of Sciences from American Type Culture Collection, Manassas, VA, USA) was routinely cultivated in a RPMI-1640 (Gibco, Carlsbad, CA, USA) nutrient medium with 10\% FBS (Hangzhou Sijiqing Biological Engineering Materials Co., Ltd., Hangzhou, China) in an incubator ventilated with $5 \% \mathrm{CO}_{2}$ at $37^{\circ} \mathrm{C}$. The cells in the exponential growth phase were used for the assay.

Cytostasis rate. The HEC-1B cells were inoculated into 96-well plates $\left(1 \times 10^{4} /\right.$ well $)$ and were routinely cultivated in an incubator

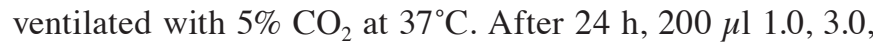
9.0 or $27.0 \mu \mathrm{mol} / 1$ celecoxib (batch number: 0408064, Pfizer, New York, NY, USA) solution was added. No drug was used in the control and blank groups for zero adjustment. A total of 3 parallel wells were used in each group. After 24, 48 and $72 \mathrm{~h}$ of cultivation, $20 \mu \mathrm{l}$ MTT solution $(5 \mathrm{mg} / \mathrm{ml})$ was added to each well. The cultivation was terminated after $4 \mathrm{~h}$. The supernate in each well was discarded and $150 \mu 1$ DMSO was added (Sigma, St. Louis, MO, USA). After agitating the solution for $10 \mathrm{~min}$, the absorbance (A490) was determined using an ELISA at $490 \mathrm{~nm}$. The cytostasis rate was calculated using the following formula: Cytostasis rate $=\left[\left(\mathrm{A}_{\text {control group }}-\mathrm{A}_{\text {test group }}\right) / \mathrm{A}_{\text {control group }}\right] \mathrm{x}$ 100. The assay was conducted three times.

Cell cycle and apoptosis. The HEC-1B cells in the logarithmic phase were inoculated into culture flasks with an area of $25 \mathrm{~cm}^{2}$, routinely cultivated in an incubator for $24 \mathrm{~h}$ and ventilated with $5 \% \mathrm{CO}_{2}$ at $37^{\circ} \mathrm{C}$ with saturated humidity. When the cells were well-grown and adherent, they were cultivated in serum-free RPMI-1640 for $12 \mathrm{~h}$. The culture fluid was drained from the test group, and $200 \mu 1$ celecoxib was added with the following concentrations: 1.0, 3.0, 9.0 and $27.0 \mu \mathrm{mol} / 1$. No drug was added to the control group. Three parallel samples were prepared for each group. After $24 \mathrm{~h}, \sim 2 \times 10^{6}$ cells were obtained from the single cell suspension from each culture flask. After centrifuging and fixation, the cells were stained with propidium iodide and were kept in the dark for $30 \mathrm{~min}$. Cell cycle and apoptosis assays were then performed in the Shanghai Cell Bank, Chinese Academy of Sciences. All assays were performed three times.

Establishment of an invasion cabin and determination of invasiveness in vitro. The bottom of the Transwell cabin was coated with a diluted solution (1:8) of $50 \mathrm{mg} / 1$ Matrigel (ID: 356243, Corning, Inc., Corning, NY, USA), air dried at $4^{\circ} \mathrm{C}$ and sterilized by vitalight lamp for $2 \mathrm{~h}$. The supernatant was discarded, and $50 \mu \mathrm{l}$ serum-free medium containing $10 \mathrm{~g} / \mathrm{l}$ BSA (Corning Inc.) was added. The samples were cultivated in an incubator at $37^{\circ} \mathrm{C}$ for $30 \mathrm{~min}$. The Transwell cabin (Corning) was placed in a 24-pore plate and $400 \mu \mathrm{l}$ conditioned medium (supernate of the HEC-1B cell culture) and the complete culture fluid were added in a 1:1 ratio. A tumor cell suspension ( 200 $\mu \mathrm{l})$ comprising RPMI-1640 culture fluid with $10 \mathrm{~g} / 1 \mathrm{BSA}, 1 \% \mathrm{FBS}$ and $2 \times 10^{5}$ cells $/ \mathrm{ml}$ was added to the cabin. After $24 \mathrm{~h}, 500 \mu \mathrm{l}$ celecoxib at concentrations of 1.0, 3.0, 9.0 and $27.0 \mu \mathrm{mol} / 1$ was added to the test groups. The control group contained no celecoxib. The Transwell cabin was taken out and washed with PBS after $24 \mathrm{~h}$. The cells above the microporous membrane were removed using a cotton swab, fixed with $95 \%$ alcohol and stained with Giemsa. Three parallel pores were formed in each group. The cell count was determined using an inverted microscope in 5 fields of vision at a magnification of $\mathrm{x} 100$. The average was used to evaluate the invasiveness.

COX-2 expression. The HEC-1B cells were plated in a 6-well plate $\left(5 \times 10^{5}\right.$ cells/well $)$ and were routinely cultivated in an incubator ventilated with $5 \% \mathrm{CO}_{2}$ at $37^{\circ} \mathrm{C}$. After $24 \mathrm{~h}$, the original culture fluid was discarded. The cells in the test groups were treated with $1 \mathrm{ml}$ celecoxib solution at concentrations of 1.0, 3.0, 9.0 and $27.0 \mu \mathrm{mol} / 1$, whereas the control group was left untreated $(n=3)$. According to the pre-cooling procedure, a lysis buffer was added and the following procedures were performed: cell quassation using an Ultrasonic Cell Disruptor, centrifuging at 10,000 rpm for $10 \mathrm{~min}$, SDS-PAGE, electrotransfer, sealing, addition of antibody, imaging and analysis of the results.

Animals and breeding. A total of 35 4-week-old BALB/c (nu/nu) nude mice from Shanghai Laboratory Animal Co. Ltd. (Shanghai, China) weighing 18-22 g were raised in SPF conditions at the Shanghai Institutes for Biological Sciences. The experiment was approved by the Ethics Committee for Animal Experiments of the Chinese Academy of Sciences.

The HEC-1B human endometrial adenocarcinoma cell line was routinely cultivated in RPMI media supplemented with $10 \%$ FBS in an incubator ventilated with $5 \% \mathrm{CO}_{2}$ at $37^{\circ} \mathrm{C}$. Cells in the logarithmic phase were harvested and lysed with $0.25 \%$ trypase-EDTA. The suspension was collected and, after centrifuging, the supernate was discarded. The cells were washed twice with a serum-free medium and centrifuged. The suspension was diluted with PBS to a concentration of $2.5 \times 10^{7}$ cells $/ \mathrm{ml}\left(5 \times 10^{6}\right.$ cells in $\left.0.2 \mathrm{ml}\right)$. The suspension $(\sim 0.2 \mathrm{ml})$ was subcutaneously injected into the groin of each mouse using a 1-ml syringe sterilized with $75 \%$ alcohol. Mice with a subcutaneous xenografted tumor $>5 \mathrm{~mm}$ in diameter were chosen as the cancer-bearing model. The cancer-bearing nude mice were randomly divided into groups A, B and C $(n=10)$. Celecoxib was dissolved in normal saline to provide two solutions of different concentrations, 10 and $5 \mathrm{mg} / \mathrm{ml}$, and $\sim 0.4 \mathrm{ml}$ celecoxib solution was administered through a gastric tube to each mouse. For groups $\mathrm{A}$ and $\mathrm{B}$, the solution concentrations were $10 \mathrm{mg} / \mathrm{ml}$ (4 mg/day) and $5 \mathrm{mg}$ / $\mathrm{ml}$ (2 mg/day), respectively. Group C was treated with normal saline. The volume of the tumor was determined every 3 days to obtain the tumor growth curve. 
Table I. Changes in cell cycle and apoptosis in HEC-1B cells following treatment with celecoxib for 24 h detected by flow cytometry.

\begin{tabular}{ccccc}
\hline & \multicolumn{3}{c}{ Cell cycle distribution $(\%)$} & \\
\cline { 2 - 4 } Celecoxib $(\mu \mathrm{mol} / \mathrm{l})$ & G0/G1 phase & S phase & G2/M phase & Apoptosis rate $(\%)$ \\
\hline 0 & $40.97 \pm 3.92$ & $32.36 \pm 2.63$ & $26.67 \pm 2.47$ & $2.78 \pm 0.20$ \\
1.0 & $45.32 \pm 4.06^{\mathrm{b}}$ & $28.83 \pm 1.45^{\mathrm{a}}$ & $25.85 \pm 1.94^{\mathrm{a}}$ & $7.21 \pm 0.80^{\mathrm{a}}$ \\
3.0 & $64.67 \pm 3.83^{\mathrm{b}}$ & $20.07 \pm 2.35^{\mathrm{a}}$ & $15.26 \pm 3.41^{\mathrm{b}}$ & $14.50 \pm 1.34^{\mathrm{a}}$ \\
9.0 & $69.53 \pm 5.06^{\mathrm{b}}$ & $16.49 \pm 1.47^{\mathrm{a}}$ & $13.98 \pm 2.85^{\mathrm{b}}$ & $19.28 \pm 1.56^{\mathrm{a}}$ \\
27.0 & $76.10 \pm 2.87^{\mathrm{a}}$ & $11.23 \pm 2.01^{\mathrm{b}}$ & $12.67 \pm 1.54^{\mathrm{a}}$ & $33.80 \pm 1.83^{\mathrm{a}}$ \\
\hline
\end{tabular}

${ }^{\mathrm{a}} \mathrm{P}<0.01 ;{ }^{\mathrm{b}} \mathrm{P}<0.05$.

Tumor inhibition rate (IR). After two weeks, the xenografted tumor was excised following the sacrifice of the mice by cervical luxation. The long diameter $(\mathrm{a}, \mathrm{mm})$ and short diameter $(\mathrm{b}, \mathrm{mm})$ of the tumor were determined. The volume of the tumor $\left(\mathrm{V}, \mathrm{mm}^{3}\right)$ and IR were calculated according to the following formulae: $\mathrm{V}=\left(\mathrm{a} \mathrm{x} \mathrm{b}^{2}\right) / 2 ; \mathrm{IR}=\left[\left(\mathrm{V}_{\text {mean control group }}\right.\right.$ $\left.\left.-\mathrm{V}_{\text {mean test group }}\right) /\left(\mathrm{V}_{\text {mean control group }}\right)\right] \mathrm{x} 100$. The tumor tissues were fixed with $4 \%$ paraformaldehyde and preserved in liquid nitrogen.

COX-2 levels and microvessel density (MVD). The COX-2 levels and MVD were determined using the immunohistochemical method. As described in the manufacturer's instructions, modifications were performed after fixing the cells in $10 \%$ methanol. The cells were then prepared as $5-\mu \mathrm{m}$ thick paraffin sections, dewaxed and hydrated. COX-2 and CD34 were diluted to 1:100 and 1:50, respectively. A positive response was characterized by a brownish yellow color under a light microscope. The standard score for immunohistochemical staining was similar to that obtained by the Rahman method. The vessels stained brown by anti-factor VIII antibodies were counted at a magnification of $x 200$. The average vessel number in the three fields of vision was used as the MVD.

Statistical analysis. The experimental data are expressed as the means \pm standard deviation. SAS6.12 package was used to proces the experimental data using the t-test, analysis of variance and correlation analysis. $\mathrm{P}<0.05$ was considered to indicate a statistically significant result.

\section{Results}

Cell proliferation. The results from the MTT assay revealed that cell proliferation was significantly inhibited by celecoxib in a time-dependent and concentration-dependent manner. The IR was 8.5 and $36.0 \%$ for 1.0 and $27.0 \mu \mathrm{mol} / 1$ celecoxib, respectively, at $24 \mathrm{~h}$, and the IR values of $27.0 \mu \mathrm{mol} / \mathrm{l}$ celecoxib were 36.0 and $77.2 \%$ at 24 and 72 h, respectively (Fig. 1). The cells exposed to celecoxib for $24 \mathrm{~h}$ were used in further experiments to avoid cell damage due to prolonged exposure to the drug.

Cell cycle and apoptosis. After treating the cells with celecoxib for $24 \mathrm{~h}$, the results from flow cytometry revealed

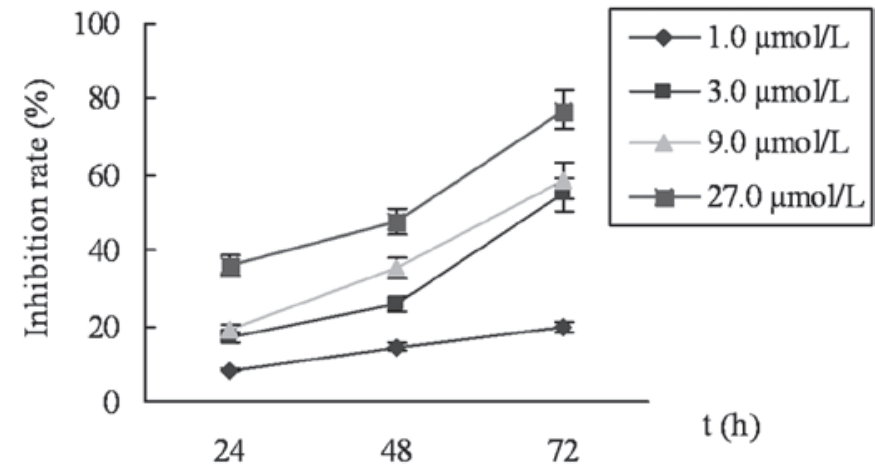

Figure 1. Changes in HEC-1B cell proliferation following treatment with different concentrations of celecoxib.

that the cell cycle was characterized by an increase in the proportion of cells in the G0/G1 phase, blockage of the G0/G1 phase, decreases in the proportion of cells in the $S$ and G2/M phases, and increases in the apoptosis peak and apoptosis rate. Statistical significance was observed between the test group and control group $(\mathrm{P}<0.05)$ (Fig. 2; Table I).

Changes in invasiveness. The results of the Transwell invasive test indicated that the HEC-1B cells were able to permeate through the polycarbonate membrane coated with Matrigel. However, the invasiveness was greatly decreased by celecoxib in a concentration-dependent manner. No statistical significance was observed between the $1.0 \mu \mathrm{mol} / 1$ test group and the control group ( $31.4 \pm 2.2$ vs. $32.9 \pm 2.1, \mathrm{P}>0.05)$. However, compared with the control group, the number of cells that permeated through the membrane was greatly decreased following treatment with $3.0,9.0$ and $27.0 \mu \mathrm{mol} / 1$ celecoxib $(17.0 \pm 2.6,12.5 \pm 2.1$ and $6.7 \pm 1.2$, respectively, $\mathrm{P}<0.01$; Fig. 3).

COX-2 expression. The results from the western blot analysis revealed that celecoxib greatly attenuated the COX-2 expression in a concentration-dependent manner. However, no significant difference was observed between the $1.0 \mu \mathrm{mol} / 1$ celecoxib test group and the control group. The inhibition of COX-2 expression followed a concentration-dependent pathway $(\mathrm{P}<0.05$; Fig. 4). 

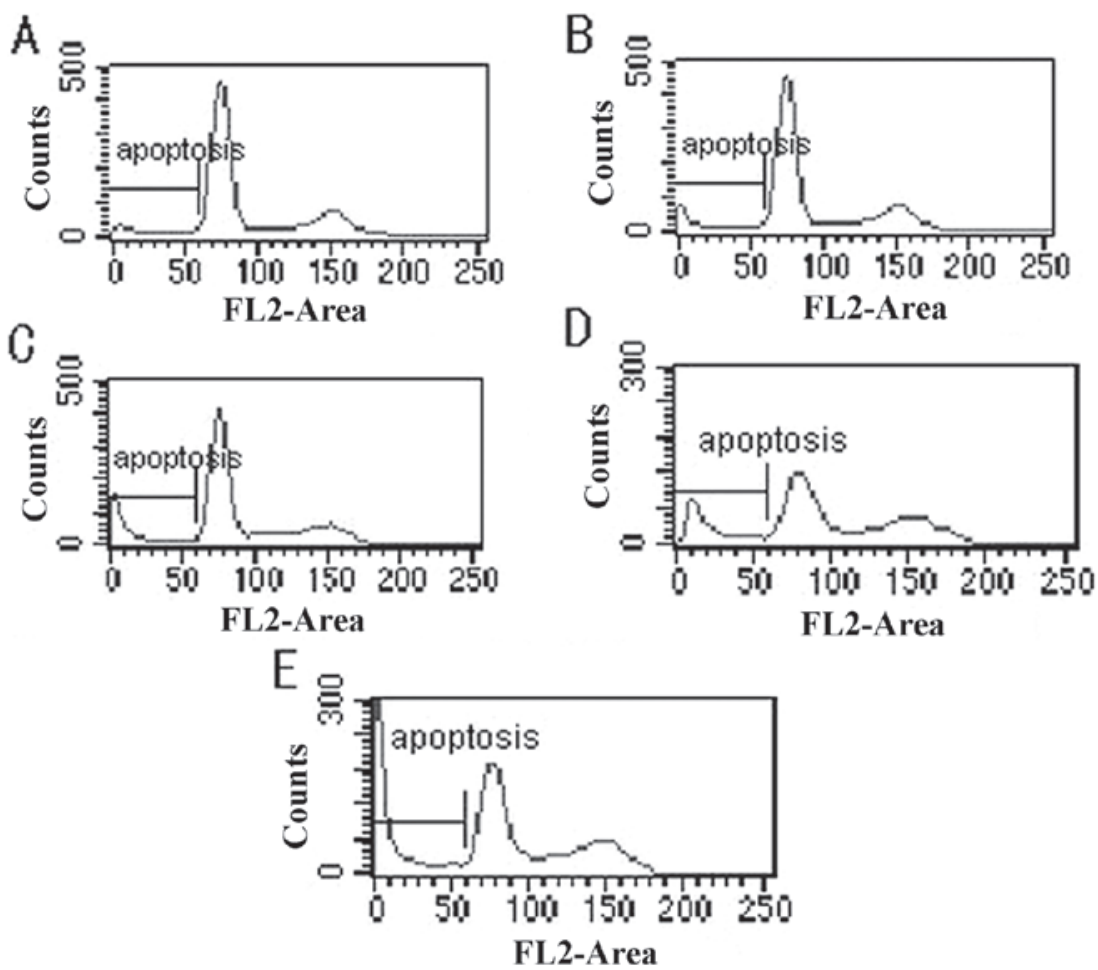

Figure 2. Apoptosis of HEC-1B cells in (A) control group and (B-E) test groups treated with 1.0, 3.0, 9.0 and $27.0 \mu$ mol/l celecoxib, respectively, for $24 \mathrm{~h}$. FL2-Area, fluorescence peak reflecting the cellular DNA content.

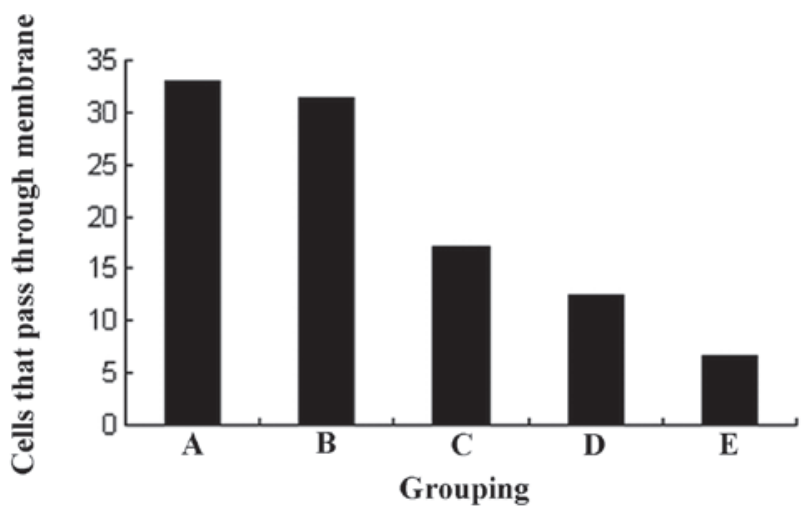

Figure 3. Effect of celecoxib on HEC-1B invasiveness. (A) Control cells ( $0 \mu \mathrm{mol} / 1$ celecoxib); (B-E) cells treated with celecoxib at concentrations of $1.0,3.0,9.0$ and $27.0 \mu \mathrm{mol} / 1$, respectively.

Endometrial adenocarcinoma model. Fourteen days after the subcutaneous inoculation, all 35 nude mice with an observed tumor growth survived with a balanced diet. According to the standards of cancer-bearing models, 30 mice were chosen for further experiments. The mice were sacrificed and their tumor tissues were excised for pathological examination using H\&E staining. The morphologies of the model and human endometrial adenocarcinoma tissues were identical. Thus, the validity of the nude mice model of human endometrial adenocarcinoma was confirmed (Figs. 5 and 6).

Xenograft growth in nude mice. The results indicated that the growth of the xenograft was significantly decreased by

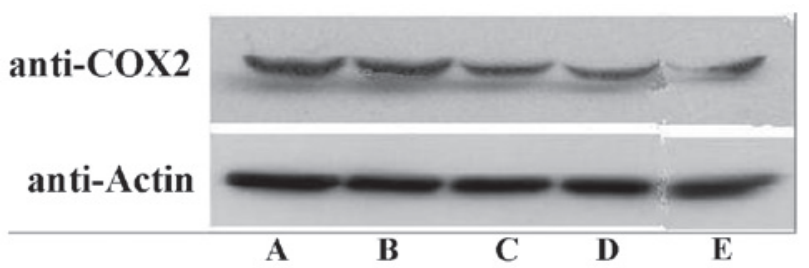

Figure 4. Expression of cyclooxygenase-2 (COX-2) in HEC-1B cells treated with celecoxib. (A) Control; (B-E) cells treated with 1.0, 3.0, 9.0 and $27.0 \mu \mathrm{mol} / 1$ celecoxib, respectively.

celecoxib in a concentration-dependent manner. The IRs were 32.4 and $48.6 \%$ for the groups treated with 2 and $4 \mathrm{mg} /$ day celecoxib, respectively. Statistical significance was observed in the difference in the weight and volume of the xenograft between the test and the control groups and between the test groups treated with different doses $(\mathrm{P}<0.05, \mathrm{P}<0.01$, respectively). The results are shown in Fig. 7 and Table II.

COX-2 expression and MVD in the xenografts. The results from the immunochemical assay indicated that COX-2 was mainly expressed in the cytoplasm of the tumor cells in the form of buffy granules. Celecoxib dose-dependently attenuated the expression of COX-2 and reduced the MVD. Statistical significance was observed in the COX-2 expression level and MVD between the test group and the control group $(\mathrm{P}<0.05$ and $\mathrm{P}<0.01$, respectively). The expression level of COX-2 was positively correlated with MVD $(r=0.921, \mathrm{P}<0.01)$ (Table III). 


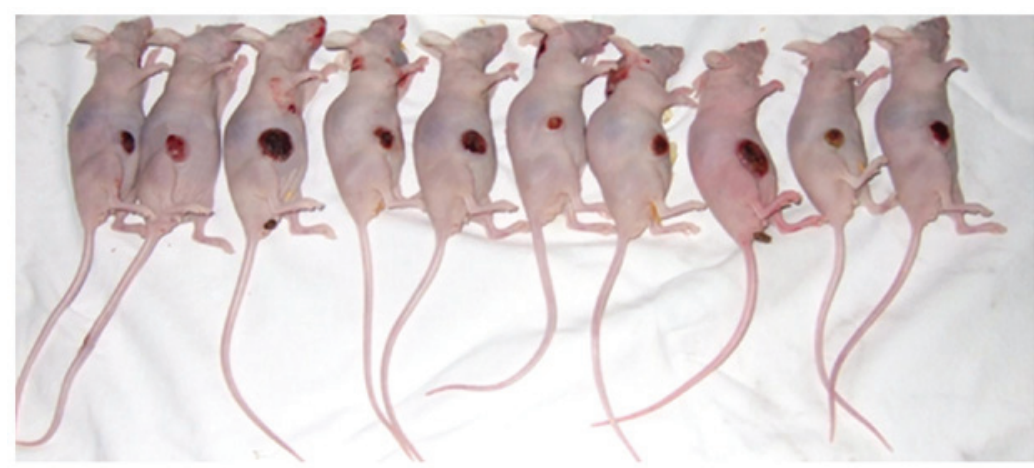

Figure 5. Cancer-bearing nude mice after sacrifice.

Table II. Alteration in transplantation volume and weight following celecoxib treatment (mean $\pm \mathrm{s}$ ).

\begin{tabular}{lccc}
\hline Group & Volume $\left(\mathrm{mm}^{3}\right)$ & Weight $(\mathrm{g})$ & IR (\%) \\
\hline C, Control & $596.5 \pm 77.3$ & $0.607 \pm 0.058$ & 0 \\
B, 2 mg/day & $403.2 \pm 53.8^{\mathrm{a}}$ & $0.41 \pm 0.062^{\mathrm{b}}$ & 32.4 \\
A, 4 mg/day & $306.7 \pm 43.6^{\mathrm{a}}$ & $0.33 \pm 0.046^{\mathrm{b}}$ & 48.6 \\
\hline
\end{tabular}

IR, inhibition rate. ${ }^{\mathrm{a}} \mathrm{P}<0.05,{ }^{\mathrm{b}} \mathrm{P}<0.01$ compared with the control group.

Table III. Effect of celecoxib on COX-2 expression and MVD in nude mice transplantation tumor.

\begin{tabular}{lccc}
\hline Group & $\mathrm{n}$ & COX-2 & MVD \\
\hline C, Control & 10 & $9.3 \pm 1.6$ & $24.6 \pm 3.7$ \\
B, 2 mg/day & 10 & $5.6 \pm 1.3^{\mathrm{a}}$ & $13.5 \pm 2.6^{\mathrm{b}}$ \\
A, 4 mg/day & 10 & $3.5 \pm 1.1^{\mathrm{a}}$ & $7.8 \pm 2.1^{\mathrm{b}}$ \\
\hline
\end{tabular}

COX-2, cyclooxygenase-2; MVD, microvessel density. ${ }^{\mathrm{a}} \mathrm{P}<0.05$; ${ }^{\mathrm{b}} \mathrm{P}<0.01$ compared with the control group; $r$, coefficient correlation of COX-2. MVD, 0.921; $\mathrm{P}<0.01$.

\section{Discussion}

Endometrial cancer, which is one of the three malignant tumors of the female genital tract, is a malignant epithelial tumor of the endometrium. COX is the key enzyme that converts arachidonic acid to prostaglandins (PGs). COX isozymes 1 and 2 are the rate-limiting enzymes in the biosynthesis of PGs. COX-1 and COX-2 convert arachidonic acid to $\mathrm{PGH}_{2}$. $\mathrm{PGH}_{2}$ is then converted to various PGs by specific synthases. COX-2 is induced by a variety of stimulants such as cytokines, growth factors, oncogens and tumors, whereas COX-1 is a non-inducible isozyme (9). Although COX-2 selective inhibitors suppress many COX-2 expressing tumor cells, the mechanism remains unclear at present. Liu et al revealed that celecoxib suppresses the growth of liver cancer cells and facilitates apoptosis (10).

During the investigation of the effect of celecoxib on the human endometrial carcinoma cell line HEC-1A, Hasegawa et al (11) demonstrated that celecoxib effectively

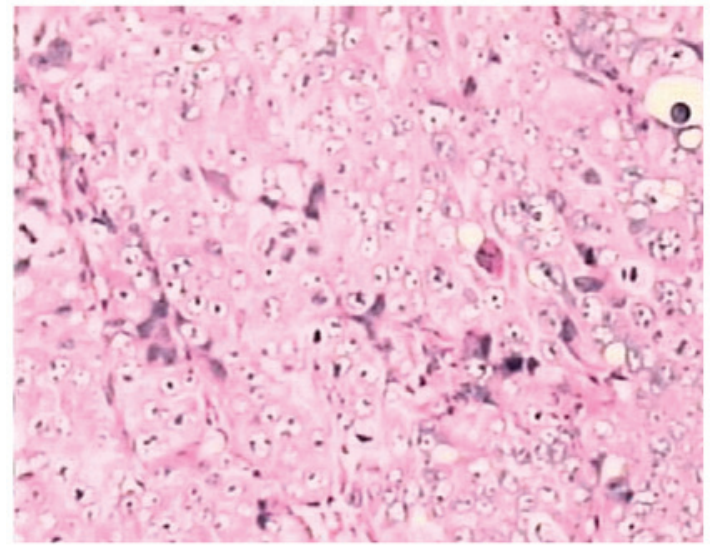

Figure 6. Pathological features of the transplant from a nude mouse (Magnification, x200).

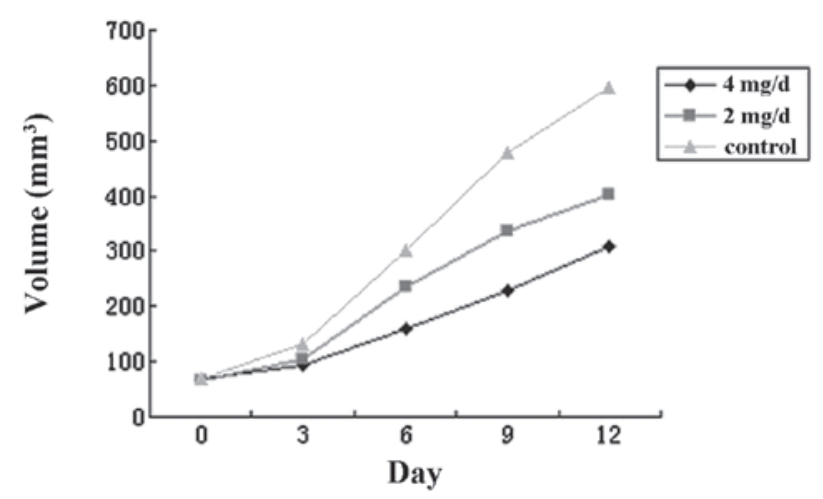

Figure 7. Growth curves of tumor xenografts in nude mice.

suppressed the proliferation of HEC-1A cells and increased the proportion of cells in the $\mathrm{G} 0 / \mathrm{G} 1$ phase (6). COX-2 is expressed in HEC-1B cells, and its expression is gradually attenuated by different concentrations of celecoxib solution (3.0-27.0 $\mu \mathrm{mol} / \mathrm{l})$. The results from the MTT assay and flow cytometry indicated that the proliferation of HEC-1B cells was markedly inhibited by celecoxib in a time- and concentration-dependent manner. After treating the cells with celecoxib for $24 \mathrm{~h}$, the HEC-1B cells were characterized by an increase in the proportion in the G0/G1 phase, blockage in the G0/G1 phase, decreases in the proportions of cells in the $\mathrm{S}$ and $\mathrm{G} 2 / \mathrm{M}$ phases, and elevated 
apoptosis peak and apoptosis rate. These results were consistent with those of Wei et al (5). Based on these results, celecoxib may induce apoptosis and inhibit proliferation by downregulating the expression of COX-2 in the HEC-1B cells.

Tumor invasion and metastasis are complicated processes involving many steps, which begin with the exfoliation of tumor cells and adhesion to the extracellular matrix and ultimately lead to degradation of the cell matrix. The tumor attaches itself to an organ to form a new metastasis following the proliferation of malignant cells. Numerous cytokines and proteins are involved in the process of tumor invasion and metastasis. In the Transwell cabin, the Matrigel coating on the polycarbonate microporous film contains laminin, fibronectin, and collagen IV extracted from the Esh sarcomas of rats which are similar components to those of the basement membrane. The Transwell test effectively imitates the invasion progress in vitro. In this test, invasiveness is characterized as the ability of the cells to pass through $8-\mu \mathrm{m}$ pore films. The results from the Transwell invasive test indicated that HEC-1B cells were capable of passing through the Matrigel-coated polycarbonate membrane, and this invasiveness was greatly decreased by celecoxib in a concentration-dependent manner. No statistical significance was observed between the control group and the test group treated with $1.0 \mu \mathrm{mol} / 1$ celecoxib $(\mathrm{P}>0.05)$. However, the number of cells that passed through the membrane greatly decreased when they were treated with $3.0,9.0$ or $27.0 \mu \mathrm{mol} / 1$ celecoxib $(\mathrm{P}<0.05)$. The present study indicated that celecoxib attenuated the invasiveness of HEC-1B cells by downregulating the expression of COX-2 (12).

The model involving nude mice with endometrial adenocarcinoma xenografts was successfully established. The validity of the model was confirmed by the observation that the pathological morphology of the model and that of the human endometrial adenocarcinoma tissue were identical. Pathological karyokinesis was observed in the endometrial adenocarcinoma tissue with a densely stained nucleus using a light microscope. An immunohistochemical assay was used to evaluate the expression of COX-2 and the MVD. The results indicated that the expression level of COX-2 and the MVD were attenuated by celecoxib in a concentration-dependent manner. Statistical significance was observed in the COX-2 expression level and MVD between the test group and the control group $(\mathrm{P}<0.05$ and $\mathrm{P}<0.01$ respectively). The expression level of COX-2 positively correlated with MVD $(\mathrm{r}=0.921, \mathrm{P}<0.01)$.

The results from in vivo experiments indicated that celecoxib inhibited the growth of the tumor xenografts. This inhibition may be related to the inhibition of COX-2 by celecoxib and a consequent inhibition of vasculogenesis, which is the prerequisite of tumorigenesis and metastasis. Thus, the inhibition of vasculogenesis is a significant indicator of the inhibition of tumor progression and metastasis. COX-2 promotes tumorigenesis through vasculogenesis induction and is catalyzed by PGs. The overexpression of COX-2 in the tumor cells may lead to the increased expression of $\mathrm{PGE}_{2}$, which is common in the early stages of tumorigenesis. The reduction of $\mathrm{PGE}_{2}$ levels due to COX-2 inhibition results in a lowered cAMP level and this promotes the apoptosis of endothelocytes and impedes capillary genesis by inhibiting anti-apoptotic key enzymes, including Akt (13). COX-2 is expressed in numerous tissues, including human lung, breast, colon, prostate and nascent blood vessel endothelium. COX-2 selective inhibitors such as celecoxib inhibited vasculogenesis in the cornea, but COX-1 inhibitors did not (14). The results indicated that COX-2 selective inhibitors suppress the growth of tumor cells by inhibiting nascent capillary growth through a number of biochemical mechanisms. The concentrations of these inhibitors affect the progression of cancer cells, and may be related to pathways involving Akt and JNK inhibition rather than the inhibition of COX-2 alone.

In summary, the present study demonstrates that the genesis, progression and invasion of endometrial adenocarcinoma is closely correlated to the overexpression of COX-2 through upstream regulation. The COX-2 selective inhibitor celecoxib inhibited the progression of endometrial adenocarcinoma. This study provides evidence for the potential of gene-targeted therapy and drug-assisted therapy in the treatment of endometrial adenocarcinoma. However, further studies are required to determine whether COX-2 selective inhibitors may be used as effective means for treating endometrial adenocarcinoma in clinical practice.

\section{References}

1. Uharcek P: Prognostic factors in endometrial carcinoma. J Obstet Gynaecol Res 34: 776-783, 2008.

2. Ohno S, Ohno Y, Suzuki N, Soma G and Inoue M: Cyclooxygenase-2 expression correlates with apoptosis and angiogenesis in endometrial cancer tissue. Anticancer Res 27: 3765-3770, 2007.

3. Li HL, Zhang HW, Chen DD, Zhong L, Ren XD and St-Tu R: JTE-522, a selective COX-2 inhibitor, inhibits cell proliferation and induces apoptosis in RL95-2 cells. Acta Pharmacol Sin 23: 631-637, 2002.

4. Wood NJ, Quinton NA, Burdall S, Sheridan E and Duffy SR: Exploring the potential chemopreventative effect of aspirin and rofecoxib on hereditary nonpolyposis colorectal cancer-like endometrial cancer cells in vitro through mechanisms involving apoptosis, the cell cycle, and mismatch repair gene expression. Int J Gynecol Cancer 17: 447-454, 2007.

5. Wei SC, Lin YS, Tsao PN, Wu-Tsai JJ, Wu CH and Wong JM: Comparison of the anti-proliferation and apoptosis-induction activities of sulindac, celecoxib, curcumin, and nifedipine in mismatch repair-deficient cell lines. J Formos Med Assoc 103: 599-606, 2004.

6. Munir I, Fukunaga K, Kanasaki H, et al: Expression of cyclooxygenase 2 by prostaglandin $\mathrm{E}(2)$ in human endometrial adenocarcinoma cell line HEC-1B. Biol Reprod 63: 933-941, 2000.

7. Gong Y, Murphy LC and Murphy LJ: Hormonal regulation of proliferation and transforming growth factors gene expression in human endometrial adenocarcinoma xenografts. J Steroid Biochem Mol Biol 50: 13-19, 1994.

8. Eitan R, Saenz CC, Venkatraman ES, et al: Pilot study prospectively evaluating the use of the measurement of preoperative sonographic endometrial thickness in postmenopausal patients with endometrial cancer. Menopause 12: 27-30, 2005.

9. Subbaramaiah K, Zakim D, Weksler BB and Dannenberg AJ: Inhibition of cyclooxygenase: a novel approach to cancer prevention. Proc Soc Exp Biol Med 216: 201-210, 1997.

10. Liu NB, Peng T, Pan C, Yao YY, Shen B and Leng J: Overexpression of cyclooxygenase-2 in human HepG2, Bel-7402 and SMMC-7721 hepatoma cell lines and mechanism of cyclooxygenase-2 selective inhibitor celecoxib-induced cell growth inhibition and apoptosis. World J Gastroenterol 11: 6281-6287, 2005.

11. Hasegawa $\mathrm{K}$, Ohashi Y, Ishikawa $\mathrm{K}$, et al: Expression of cyclooxygenase- 2 in uterine endometrial cancer and anti-tumor effects of a selective COX-2 inhibitor. Int J Oncol 26: 1419-1428, 2005.

12. Cao Y and Prescott SM: Many actions of cyclooxygenase-2 in cellular dynamics and in cancer. J Cell Physiol 190: 279-286, 2002.

13. Fosslien E: Molecular pathology of cycloxygenase-2 in neoplagia. J Ann Clin Lab Sci 30: 3-21, 2000.

14. Masferrer JL, Leahy KM and Koki AT: Antiangiogenic and antitumor activities of cyclooxygenase- 2 inhibitors. Cancer Res 60: 1306-1311, 2000. 